\title{
Serotonergic mechanism of the relieving effect of bee venom acupuncture on oxaliplatin-induced neuropathic cold allodynia in rats
}

Ji-Hye Lee ${ }^{1}$, Dong Xing Li ${ }^{2}$, Heera Yoon ${ }^{2}$, Donghyun Go ${ }^{1}$, Fu Shi Quan ${ }^{3}$, Byung-II Min ${ }^{1,4}$ and Sun Kwang Kim ${ }^{1,2^{*}}$

\begin{abstract}
Background: Oxaliplatin, an important chemotherapy drug for advanced colorectal cancer, often induces peripheral neuropathy, especially cold allodynia. Our previous study showed that bee venom acupuncture (BVA), which has been traditionally used in Korea to treat various pain symptoms, potently relieves oxaliplatin-induced cold allodynia in rats. However, the mechanism for this anti-allodynic effect of BVA remains poorly understood. We investigated whether and how the central serotonergic system, a well-known pathway for acupuncture analgesia, mediates the relieving effect of BVA on cold allodynia in oxaliplatin-injected rats.
\end{abstract}

Methods: The behavioral signs of cold allodynia in Sprague-Dawley (SD) rats were induced by a single injection of oxaliplatin ( $6 \mathrm{mg} / \mathrm{kg}$, i.p.). Before and after BVA treatment, the cold allodynia signs were evaluated by immersing the rat's tail into cold water $\left(4^{\circ} \mathrm{C}\right)$ and measuring the withdrawal latency. For BVA treatment, a diluted BV $(0.25 \mathrm{mg} / \mathrm{kg})$ was subcutaneously administered into Yaoyangguan (GV3) acupoint, which is located between the spinous processes of the fourth and the fifth lumbar vertebra. Serotonin was depleted by a daily injection of DL-p-chlorophenylalanine (PCPA, $150 \mathrm{mg} / \mathrm{kg}$, i.p.) for 3 days. The amount of serotonin in the spinal cord was measured by ELISA. Serotonergic receptor antagonists were administered intraperitoneally or intrathecally before BVA treatment.

Results: The serotonin levels in the spinal cord were significantly increased by BVA treatment and such increase was significantly reduced by PCPA. This PCPA pretreatment abolished the relieving effect of BVA on oxaliplatin-induced cold allodynia. Either of methysergide (mixed 5- $\mathrm{HT}_{1} / 5-\mathrm{HT}_{2}$ receptor antagonist, $1 \mathrm{mg} / \mathrm{kg}$, i.p.) or MDL-72222 $\left(5-\mathrm{HT}_{3}\right.$ receptor antagonist, $1 \mathrm{mg} / \mathrm{kg}$, i.p) blocked the anti-allodynic effect of BVA. Further, an intrathecal injection of MDL-72222 $(12 \mu \mathrm{g})$ completely blocked the BVA-induced anti-allodynic action, whereas NAN-190 (5-HT 1 A receptor antagonist, $15 \mu$ g, i.t.) or ketanserin (5- $\mathrm{HT}_{2 \mathrm{~A}}$ receptor antagonist, $30 \mu \mathrm{g}$, i.t.) did not.

Conclusions: These results suggest that BVA treatment alleviates oxaliplatin-induced acute cold allodynia in rats via activation of the serotonergic system, especially spinal $5-\mathrm{HT}_{3}$ receptors. Thus, our findings may provide a clinically useful evidence for the application of BVA as an alternative therapeutic option for the management of peripheral neuropathy, a dose-limiting side effect that occurs after an administration of oxaliplatin.

Keywords: Bee venom acupuncture, Cold allodynia, Oxaliplatin, Rat, Serotonin

\footnotetext{
* Correspondence: skkim77@khu.ac.kr

'Department of East-west Medicine, Graduate School, Kyung Hee University,

Seoul 130-701, Republic of Korea

${ }^{2}$ Department of Physiology, College of Korean Medicine, Kyung Hee

University, Seoul 130-701, Republic of Korea

Full list of author information is available at the end of the article
} 


\section{Background}

Oxaliplatin, a third-generation platinum-based chemotherapy agent, is considered a central component in the treatment of advanced colorectal cancer $[1,2]$. The most important side effect of oxaliplatin treatment is a peripheral neuropathy that has unique characteristics and represents a major dose-limiting toxicity [3,4]. This unpleasant acute neurosensory toxicity with dysesthesia of the distal extremities and perioral region occurs shortly after an infusion in as much as $90 \%$ of the patients. These symptoms can be worsened or triggered by cold [5-7]. However, the mechanisms and the effective treatment for oxaliplatininduced cold allodynia still remain to be elucidated [8]. Therefore it is worth searching for potential therapeutic options for the management of oxaliplatin-induced neuropathic pain and revealing their action mechanisms.

Bee venom acupuncture (BVA), a kind of chemical stimulation of peripheral nerves (i.e. a subcutaneous injection of diluted BV into one or more acupoints) [9], has long been used in Korea, to relieve pain and to treat inflammatory diseases such as rheumatoid arthritis and osteoarthritis [10-12]. Several animal studies have demonstrated that the analgesic effects of BVA are mediated mainly by activation of $\alpha 2$-adrenergic and/or serotonergic receptors in various pain models, such as nerve injuryinduced neuropathic pain, acetic acid-induced visceral pain and inflammatory pain [12-15]. In our recent study [16], we showed that BVA $(0.25 \mathrm{mg} / \mathrm{kg})$ treatment at Yaoyangguan (GV3) acupoint significantly attenuated oxaliplatin-induced cold allodynia in rats, which was greater than BVA treatment at the other well-known acupoints for acupuncture analgesia (e.g. Zusanli [ST36] and Quchi [LI11]). However, this anti-allodynic action of BVA was only partially mediated by the noradrenergic system [16]. In addition, the endogenous opioid system that plays a key role in mediating electroacupuncture (EA)induced anti-allodynia in oxaliplatin-injected rats [17] was not involved in such BVA effect [16]. These results suggest that another analgesic system might be responsible for the relieving effect of BVA on oxaliplatininduced neuropathic cold allodynia.

The present study was performed to examine whether the suppressive effect of BVA on cold allodynia in oxaliplatin-injected rats is mediated by the serotonergic inhibitory system, which has been regarded as one of the major non-opioid anti-allodynic pathway for acupuncture or EA $[18,19]$. We further investigated which subtype of serotonergic receptors is specifically implicated in BVA-induced anti-allodynic action. We report here that BVA treatment exerts its strong relieving effect on oxaliplatin-induced cold allodynia mainly via the activation of spinal $5-\mathrm{HT}_{3}$ receptors, providing a basic evidence for the use of BVA treatment in the management of peripheral neuropathy in oxaliplatin-administered subjects.

\section{Methods}

Animals

Young adult male Sprague-Dawley rats [Sam:TacN(SD) BR, 200-220 g, 7 weeks old] were housed in cages (3-4 rats per cage) with water and food available ad libitum. The room was maintained with a 12 h-light/dark cycle (a light cycle; 08:00-20:00, a dark cycle; 20:00-08:00) and kept at $23 \pm 2^{\circ} \mathrm{C}$. All animals were acclimated in their cages for 1 week prior to any experiments. All procedures involving animals were approved by the Institutional Animal Care and Use Committee of Kyung Hee University (KHUASP(SE)-14-010) and were conducted in accordance with the guidelines of the International Association for the Study of Pain [20].

\section{Oxaliplatin injection}

As described previously [21,22], oxaliplatin (Sigma, St Louis, MO, USA) was dissolved in a $5 \%$ glucose (Sigma) solution at a concentration of $2 \mathrm{mg} / \mathrm{mL}$ and was intraperitoneally administered at $6 \mathrm{mg} / \mathrm{kg}$. The same volume of $5 \%$ glucose solution was injected in the vehicle control group.

\section{Behavioral test}

To estimate whether cold allodynia was induced, cold immersion test was carried out as described previously $[18,23,24]$. Briefly, each animal was lightly immobilized in a plastic holder and its tail was drooped for a proper application of cold water stimuli. The rats were adapted to the holder for 2 days before starting behavioral tests. The tail was immersed in $4^{\circ} \mathrm{C}$ water, and then the tail withdrawal latency (TWL) was measured with a cut-off time of 15 seconds. The cold immersion test was repeated five times at $5 \mathrm{~min}$ intervals. When calculating the average latency, the cut-off time was assigned to the normal responses. The average latency was taken as a measure for the severity of cold allodynia; a shorter TWL was interpreted as more severe allodynia.

Because our previous study [17] showed that a significant cold allodynia sign is induced from 3 days after a single oxaliplatin $(6 \mathrm{mg} / \mathrm{kg}$, i.p.) injection and lasted up to 1 week after an injection, we tested whether and how the serotonergic system mediates the relieving effect of BVA on cold allodynia from 3 to 7 days after an oxaliplatin administration. In general, we replicated the experiments twice.

\section{BVA treatment}

We previously showed that the optimal acupoint of BVA-induced anti-allodynia in oxaliplatin-injected rats is Yaoyangguan (GV3) acupoint, and that low doses of BVA $(0.25 \mathrm{mg} / \mathrm{kg}$ and $1.0 \mathrm{mg} / \mathrm{kg})$ at GV3 is more effective than a high dose of BVA $(2.5 \mathrm{mg} / \mathrm{kg})$ [16]. Thus, in this study, BV $(0.25 \mathrm{mg} / \mathrm{kg})$ dissolved in normal saline 
$(\mathrm{N} / \mathrm{S}, 0.05 \mathrm{cc})$ was injected subcutaneously at GV3 acupoint, which is located between the spinous processes of the fourth and the fifth lumbar vertebrae [25]. To the control group, only $0.05 \mathrm{cc}$ of N/S was injected subcutaneously at the same acupoint.

After baseline cold sensitivity was measured, BV $(0.25 \mathrm{mg} / \mathrm{kg})$ and $\mathrm{N} / \mathrm{S}$ were injected subcutaneously at GV3, respectively. The cold immersion test was performed again at $30 \mathrm{~min}$ after BVA.

\section{Depletion of serotonin}

Rats were intraperitoneally administered with DL-pchlorophenylalanine (PCPA, Sigma, an inhibitor of serotonin synthesis, $150 \mathrm{mg} / \mathrm{kg} /$ day) or vehicle (N/S) for three days. The dosage and treatment course of PCPA has been widely used to deplete 5-HT stores [26,27]. On the day after the final injection of PCPA, oxaliplatin was administerd as described.

\section{Antagonists}

Oxaliplatin-injected rats were divided randomly into four groups: $\mathrm{N} / \mathrm{S}+\mathrm{BV}(n=7), \mathrm{DMSO}+\mathrm{BV}(n=4)$, methysergide $+\mathrm{BV}(n=7)$, and MDL-72222 + BV $(n=7)$. Methysergide maleate (mixed $5-\mathrm{HT}_{1} / 5-\mathrm{HT}_{2}$ receptor antagonist) and 3-tropanyl-3,5-dichlorobenzoate (MDL72222, $5-\mathrm{HT}_{3}$ receptor antagonist) were dissolved in N/S or $20 \%$ dimethyl sulfoxide (DMSO) to a concentration of $1 \mathrm{mg} / \mathrm{ml}$. After baseline cold sensitivity was checked, the four groups were treated intraperitoneally with N/S, 20\% DMSO, methysergide $(1 \mathrm{mg} / \mathrm{kg})$ and MDL-72222 $(1 \mathrm{mg} / \mathrm{kg})$, respectively. Twenty minutes later, all groups were treated subcutaneously with $0.25 \mathrm{mg} / \mathrm{kg}$ of BV at GV3 acupoint. The cold immersion test was performed again 30 min after BVA.

To further identify which spinal serotonergic receptor subtypes mediate BVA-induced anti-allodynia, oxaliplatininjected rats in a different set of experiments were divided randomly into five groups: $\mathrm{N} / \mathrm{S}+\mathrm{BV}(n=7), \mathrm{DMSO}+\mathrm{BV}$ $(n=3), \mathrm{NAN}-190+\mathrm{BV}(n=8)$, ketanserin $+\mathrm{BV}(n=8)$, and MDL-72222 + BV $(n=8)$. Ketanserin tartrate $\left(5-\mathrm{HT}_{2 \mathrm{~A}}\right.$ receptor antagonist, $30 \mu \mathrm{g}$ ) was dissolved in $50 \mu \mathrm{l} \mathrm{N} / \mathrm{S}$. 1-(2-methoxyphenyl)-4-(4-[2-phthalimido]butyl) piperazine hydrobromide (NAN-190, 5- $\mathrm{HT}_{1 \mathrm{~A}}$ receptor antagonist, $15 \mu \mathrm{g})$, and MDL-72222 (12 $\mu \mathrm{g})$ were dissolved in $50 \mu \mathrm{l}$ $20 \%$ DMSO. Drugs were administered intrathecally under isoflurane anesthesia with the direct lumbar puncture as described previously [28]. Briefly, $50 \mu \mathrm{l}$ of an antagonist was injected through the L3-L4 intervertebral space, which successfully delivers the drugs to the lower lumbar and sacral spinal cord segments. BVA was performed at $10 \mathrm{~min}$ after the intrathecal injection of an antagonist and the cold immersion test was performed again 30 min after BVA.
All drugs were obtained from Tocris Cookson, UK. The doses of antagonists were selected based on previously published studies that show selectivity for the individual receptor subtypes [18,29-32].

\section{ELISA}

To investigate whether BV treatment increases the quantity of serotonin and whether PCPA decreases that, rats were divided randomly into three groups: Vehicle $+N / S$, Vehicle + BV, and PCPA + BV ( $n=5 /$ group $)$. All the animals having oxliplatin-induced cold allodynia signs were sacrificed 30 minutes after BV or N/S treatment, and the lumbar spinal cords of L4 L5 were extracted out on an ice-cold Petri dish as per Glowinski and Iversen [33] and stored at $-70^{\circ} \mathrm{C}$ until the day of analysis. The amount of total protein in the spinal cord samples was measured with the PCA protein assay (PIERCE, USA). Serotonin contents were quantified with the rat 5-HT ELISA kit (LDN, Germany: Catalogue No. BA E-5900; Sensitivity, $0.005 \mathrm{ng} / \mathrm{ml}$; Specificity, $100 \%$ cross-reactivity for serotonin) according to the manufacturer's instructions.

\section{Statistical analysis}

All the data are presented as mean \pm SEM. Statistical analysis was done with Prism 5.0 (Graph Pad Software, USA). Paired $t$-test or one-way ANOVA followed by Dunnett's multiple comparison test was used for statistical analysis. In all cases, $p<0.05$ was considered significant.

\section{Results}

\section{Effects of 5-HT depletion with PCPA on BVA-induced} anti-allodynia in oxaliplatin-injected rats

To determine whether the serotonergic system is involved in the anti-allodynic effect of BVA, we evaluated the effect of depletion of central 5-HT by PCPA on the BVA effect. As shown in Figure 1a, the levels of 5-HT in the spinal cord measured by ELISA were significantly increased after BVA treatment at GV3 $(p<0.01$, Vehicle $+\mathrm{N} / \mathrm{S}$ vs Vehicle $+\mathrm{BV})$. This marked increase in spinal $5-\mathrm{HT}$ levels by BVA was significantly blocked by PCPA pretreatment $(p<0.05$, Vehicle + BV vs. PCPA + BV $)$. We also confirmed the depletion of 5-HT in the hypothalamus by PCPA (data not shown). These results indicate that BVA treatment markedly increases the amount of central 5-HT, especially in the spinal cord, and PCPA prevents such 5 -HT increase by BVA.

Figure 1b shows the effect of 5-HT depletion on the relieving effect of BVA on cold allodynia in oxaliplatininjected rats. The control group (vehicle (N/S) pretreatment) showed a significant increase in TWL after BVA treatment $(p<0.001)$, whereas the depletion of 5 -HT by PCPA pretreatment blocked the anti-allodynic effect of BVA $(p>0.05)$. These results suggest that the serotonergic 

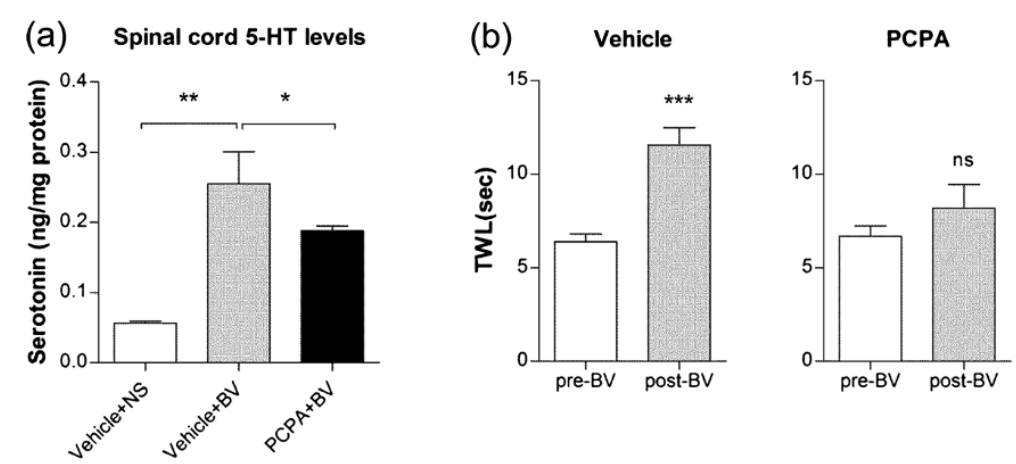

Figure 1 Effects of PCPA on BVA-induced increases in 5-HT and TWL in oxaliplatin-injected rats. (a) Levels of 5-HT in the spinal cord measured with ELISA. Vehicle + N/S, Vehicle + BV, and PCPA + BV ( $n=5 /$ group). Data are presented as mean \pm SEM. ${ }^{*} p<0.05$, ${ }^{*} p<0.01$, by one-way ANOVA followed by Dunnet's test. (b) PCPA, but not vehicle pretreatment ( $n=8 /$ group), blocked the significant increase in TWL by BVA at GV3 acupoint. Data are presented as mean \pm SEM. ${ }^{* * *} p<0.001$, ns $=$ no significant, by paired t-test.

system plays a major role in mediating the analgesic effect of BVA on oxaliplatin-induced cold allodynia.

\section{Effects of serotonergic receptor antagonists on BVA-induced} anti-allodynia in oxaliplatin-injected rats

To investigate which subtype of serotonergic receptors is specifically implicated in the relieving effect of BVA on oxaliplatin-induced cold allodynia, we first tested the effects of a systemic injection of methysergide (mixed $5-\mathrm{HT}_{1} / 5-\mathrm{HT}_{2}$ receptor antagonist, $1 \mathrm{mg} / \mathrm{kg}$, i.p.) or MDL-72222 (5- $\mathrm{HT}_{3}$ receptor antagonist, $1 \mathrm{mg} / \mathrm{kg}$, i.p.) on BVA-induced anti-allodynia. As shown in Figure 2, the N/S or $20 \%$ DMSO control group showed a significant increase in TWL after BVA treatment $(p<0.01)$, whereas both experimental groups (methysergide or MDL-72222 pretreated group) exhibited no significant difference in TWL before and after BVA $(p>0.05)$.

We further confirmed that an intrathecal injection of MDL-72222 (12 $\mu \mathrm{g})$ completely blocked the BVA-induced anti-allodynic action in oxaliplatin-injected rats $(p>0.05$, Figure 3d). However, as similar to the N/S or $20 \%$ DMSO control group, an intrathecal administration of NAN-190 $\left(5-\mathrm{HT}_{1 \mathrm{~A}}\right.$ receptor antagonist, $\left.15 \mu \mathrm{g}\right)$ or ketanserin $\left(5-\mathrm{HT}_{2 \mathrm{~A}}\right.$ receptor antagonist, $30 \mu \mathrm{g}$ ) did not block the anti-allodynic effect of BVA (Figure 3a-c). These results suggest that BVA alleviates cold allodynia in oxaliplatin-injected rats mainly via the activation of spinal $5-\mathrm{HT}_{3}$ receptors.

\section{Discussion}

Oxaliplatin, an important chemotherapy drug active against colorectal cancer [1,2], induces peripheral neuropathy triggered or aggravated in cold conditions even after a single administration [21,22]. There are few researches showing the effective treatment for the established neuropathic pain induced by oxaliplatin [8]. The potential therapeutic options are thus critically needed to manage this neuropathic pain for helping the patients overcome cancer and improving their quality of life. Our previous study demonstrated for the first time that BVA has a potent relieving effect on oxaliplatininduced cold allodynia in rats.

Unlike the EA-induced analgesia mainly involving the endogenous opioid system, the analgesic effects of BVA are known to be mediated by the non-opioid, descending noradrenergic system $[12,15,34,35]$. We recently demonstrated that EA significantly attenuates oxaliplatin-induced
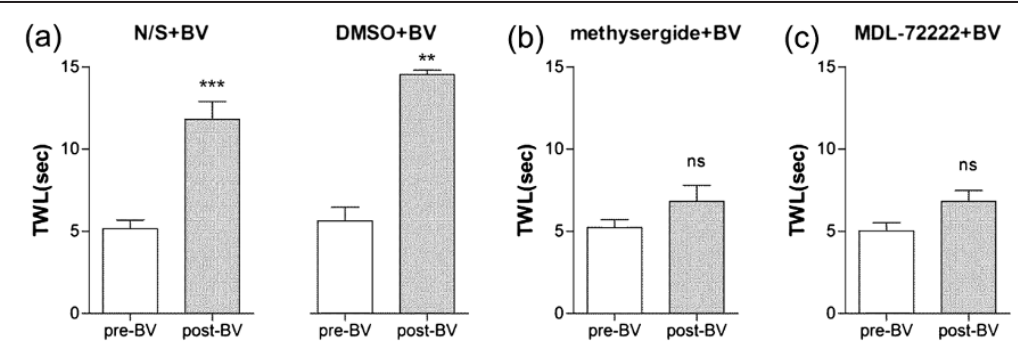

Figure 2 Effects of systemic injection of 5-HT antagonists on BVA-induced anti-allodynic action. The behavioral tests for cold allodynia were performed before an intraperitoneal injection of antagonists and after BVA treatment in the four groups of animals: (a) N/S $+B V($ left, $n=7)$ and DMSO + BV (right, $n=4)$, (b) methysergide + BV, and (c) MDL-72222+ BV ( $n=7 /$ group). Data are presented as mean \pm SEM. ${ }^{* *} p<0.01,{ }^{* * *} p<0.001$, ns $=$ no significant, by paired t-test. 

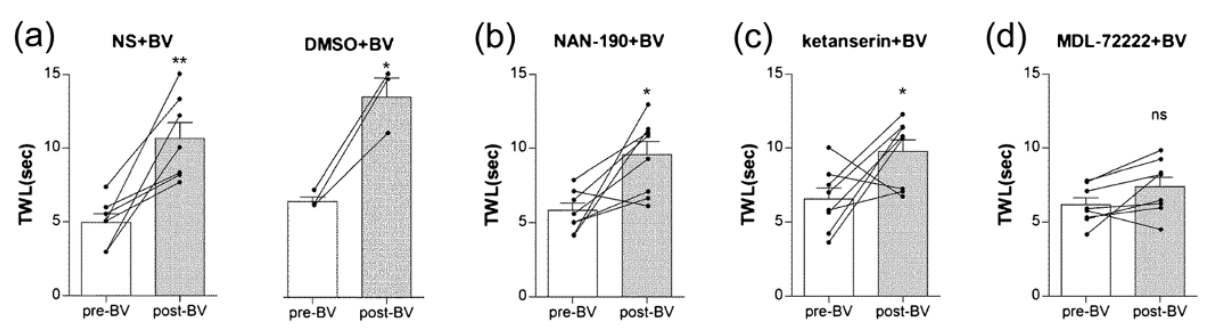

Figure 3 Effects of intrathecal injection of 5-HT antagonists on BVA-induced anti-allodynic action. The behavioral tests for cold allodynia were performed before an intrathecal injection of antagonists and after BVA treatment in the five groups of animals: (a) N/S $+B V(l e f t, n=7)$ and DMSO + BV (right, $n=3$ ), (b) NAN-190 + BV, (c) ketanserin + BV, and (d) MDL-72222 + BV ( $n=8 /$ group). Data are presented as mean \pm SEM (bar graph) and individual traces in TWL change. ${ }^{*} p<0.05,{ }^{* *} p<0.01, \mathrm{~ns}=$ no significant, by paired t-test.

cold allodynia in rats via the activation of the endogenous opioids, not the noradrenergic system [17]. However, the anti-allodynic effect of BVA in the same rat model was shown to be only partially mediated by the noradrenergic analgesic system [16]. Therefore, the neurochemical mechanism of the BVA effect on oxaliplatin-induced neuropathic pain still remains unclear.

In the present study, we focused on the other nonopioid analgesic pathway, the serotonergic inhibitory system. This serotonergic system is one of the well-known non-opioid mediators for acupuncture or EA analgesia [19] and a study by Lee and his colleagues reported that the descending serotonergic system is also involved in the antinociceptive effect of BVA in the rat formalin pain model [14]. In the present study, we observed that BVA treatment significantly increases the levels of spinal 5-HT and the TWL in oxaliplatin-injected rats. Such BVA effects were blocked by PCPA depletion of 5-HT (Figure 1). This implies that BVA exerts a potent analgesic effect on oxaliplatin-induced cold allodynia by activating the spinal serotonergic inhibitory system.

It has been known that spinal administration of 5-HT produces analgesic effects, depending on the receptor type activated and dosage use [36-38]. And the analgesic effect of serotonin is reported to be mediated by the descending pain inhibitory system from periaqueductal grey, nucleus raphe magnus and finally spinal serotonergic receptors $[39,40]$. Among the several subtypes of serotonin receptors $\left(5-\mathrm{HT}_{1-7}\right), 5-\mathrm{HT}_{1}, 5-\mathrm{HT}_{2}$ and $5-\mathrm{HT}_{3}$ receptors are known to be the most commonly implicated in spinal pain processing [32,41,42]. In this study, a systemic injection of methysergide (mixed $5-\mathrm{HT}_{1} / 5-\mathrm{HT}_{2}$ receptor antagonist) or MDL-72222 (5- $\mathrm{HT}_{3}$ receptor antagonist) prevented the relieving effect of BVA on cold allodynia (Figure 2). Our additional experiments (Figure 3) further showed that the BVA effect was blocked only by an intrathecal injection of MDL-72222, but not by an intrathecal injection of NAN-190 (5- $\mathrm{HT}_{1 \mathrm{~A}}$ receptor antagonist) or ketanserin (5- $\mathrm{HT}_{2 \mathrm{~A}}$ receptor antagonist). The discrepancy in the results between systemic and intrathecal administration of antagonists might be due to the use of non-selective antagonist, methysergide for the systemic injection experiment. Also, individual differences in the sensitivity of the rats to intrathecal NAN-190 or ketanserin might contribute to this discrepancy. As shown in Figure $3 \mathrm{~b}$ and $\mathrm{c}$, the individual changes in TWL before and after BVA treatment in NAN-190 or ketanserin pre-treated rats might be divided into two distinct clusters; three responsive rats and five non-responsive rats to either of the two antagonists. However, both of a systemic injection and an intrathecal injection of MDL-72222 similarly blocked the BVA anti-allodynic effect (Figure 3d). This result is in consistent with the other studies showing that spinal $5-\mathrm{HT}_{3}$ receptors have antinociceptive roles [43-45]. Thus, our data strongly suggest that spinal $5-\mathrm{HT}_{3}$ receptors play an important role in the BVA-induced anti-allodynic action in oxaliplatin-injected rats.

\section{Conclusions}

In conclusion, this study clearly demonstrates a key role of the serotonergic inhibitory system in the relieving effect of BVA on oxaliplatin-induced neuropathic cold allodynia, and specifically, spinal $5-\mathrm{HT}_{3}$ receptors are activated to exert the anti-allodynic effect of BVA. These results provide a basic evidence for the application of BVA as an alternative therapeutic option for the management of oxaliplatininduced peripheral neuropathy and may raise the possibility of the combinational use of BVA with well-known analgesics, such as morphine, gabapentin and antidepressants.

\section{Competing interests}

The authors declare that they have no competing interests.

\section{Authors' contributions}

$J H L, B I M$ and SKK contributed to the conception and design of the study. $J H L, D X L, H Y, D G, F S Q$ and SKK performed the experiments and analyzed the data. JHL, DG, BIM and SKK wrote the manuscript. All authors read and approved the final manuscript.

\section{Acknowledgements}

This work was supported by the National Research Foundation of Korea (NRF) grant funded by the Korea government (NRF-2013R1A1A1012403). We thank Drs. Lee G, Moon HJ, Lim BS and Kim WJ for excellent technical supports and discussions on the experiments and manuscript. 


\section{Author details}

'Department of East-west Medicine, Graduate School, Kyung Hee University, Seoul 130-701, Republic of Korea. ${ }^{2}$ Department of Physiology, College of Korean Medicine, Kyung Hee University, Seoul 130-701, Republic of Korea. ${ }^{3}$ Department of Medical Zoology, School of Medicine, Kyung Hee University, Seoul 130-701, Republic of Korea. ${ }^{4}$ Department of Physiology, School of Medicine, Kyung Hee University, Seoul 130-701, Republic of Korea.

Received: 30 July 2014 Accepted: 2 December 2014

Published: 6 December 2014

\section{References}

1. Argyriou AA, Briani C, Cavaletti G, Bruna J, Alberti P, Velasco R, Lonardi S, Cortinovis D, Cazzaniga M, Campagnolo M, Santos C, Kalofonos HP: Advanced age and liability to oxaliplatin-induced peripheral neuropathy: post hoc analysis of a prospective study. Eur J Neurol 2013, 20(5):788-794.

2. Zedan AH, Hansen TF, Svenningsen AF, Vilholm OJ: Oxaliplatin-Induced Neuropathy in Colorectal Cancer: Many Questions With Few Answers. Clin Colorectal Cancer 2014, 13(2):73-80.

3. Argyriou AA, Bruna J, Marmiroli P, Cavaletti G: Chemotherapy-induced peripheral neurotoxicity (CIPN): an update. Crit Rev Oncol/Hematol 2012, 82(1):51-77.

4. Di Cesare ML, Pacini A, Bonaccini L, Zanardelli M, Mello T, Ghelardini C Morphologic features and glial activation in rat oxaliplatin-dependent neuropathic pain. J Pain 2013, 14(12):1585-1600

5. Wilson RH, Lehky T, Thomas RR, Quinn MG, Floeter MK, Grem JL: Acute oxaliplatin-induced peripheral nerve hyperexcitability. J Clin Oncol 2002, 20(7):1767-1774

6. Renn CL, Carozzi VA, Rhee P, Gallop D, Dorsey SG, Cavaletti G: Multimodal assessment of painful peripheral neuropathy induced by chronic oxaliplatin-based chemotherapy in mice. Mol Pain 2011, 7:29.

7. Broomand A, Jerremalm E, Yachnin J, Ehrsson H, Elinder F: Oxaliplatin neurotoxicity-no general ion channel surface-charge effect. J Negative Results Biomed 2009, 8:2.

8. Wolf S, Barton D, Kottschade L, Grothey A, Loprinzi C: Chemotherapy-induced peripheral neuropathy: prevention and treatment strategies. Eur $J$ Cancer 2008, 44(11):1507-1515. Oxford, England: 1990.

9. Yoon SY, Yeo JH, Han SD, Bong DJ, Oh B, Roh DH: Diluted bee venom injection reduces ipsilateral mechanical allodynia in oxaliplatin-induced neuropathic mice. Biol Pharm Bull 2013, 36(11):1787-1793.

10. Billingham ME, Morley J, Hanson JM, Shipolini RA, Vernon CA: Letter: An anti-inflammatory peptide from bee venom. Nature 1973, 245(5421):163-164.

11. Somerfield SD, Brandwein S: Bee venom and adjuvant arthritis. J Rheumatol 1988, 15(12):1878.

12. Roh DH, Kwon YB, Kim HW, Ham TW, Yoon SY, Kang SY, Han HJ, Lee HJ, Beitz AJ, Lee JH: Acupoint stimulation with diluted bee venom (apipuncture) alleviates thermal hyperalgesia in a rodent neuropathic pain model: involvement of spinal alpha 2-adrenoceptors. J Pain 2004, 5(6):297-303.

13. Kwon YB, Kang MS, Han HJ, Beitz AJ, Lee JH: Visceral antinociception produced by bee venom stimulation of the Zhongwan acupuncture point in mice: role of alpha(2) adrenoceptors. Neurosci Lett 2001, 308(2):133-137.

14. Kim HW, Kwon YB, Han HJ, Yang IS, Beitz AJ, Lee JH: Antinociceptive mechanisms associated with diluted bee venom acupuncture (apipuncture) in the rat formalin test: involvement of descending adrenergic and serotonergic pathways. Pharmacol Res 2005, 51(2):183-188.

15. Baek YH, Huh JE, Lee JD, Choi do Y, Park DS: Antinociceptive effect and the mechanism of bee venom acupuncture (Apipuncture) on inflammatory pain in the rat model of collagen-induced arthritis: Mediation by alpha2-Adrenoceptors. Brain Res 2006, 1073-1074:305-310.

16. Lim BS, Moon HJ, Li DX, Gil M, Min JK, Lee G, Bae H, Kim SK, Min BI: Effect of bee venom acupuncture on oxaliplatin-induced cold allodynia in rats. Evidence-based Complement Alternative Med 2013, 2013:369324.

17. Moon HJ, Lim BS, Lee DI, Ye MS, Lee G, Min BI, Bae H, Na HS, Kim SK: Effects of electroacupuncture on oxaliplatin-induced neuropathic cold hypersensitivity in rats. J Physio/ Sci 2014, 64(2):151-156.

18. Kim SK, Park JH, Bae SJ, Kim JH, Hwang BG, Min BI, Park DS, Na HS: Effects of electroacupuncture on cold allodynia in a rat model of neuropathic pain: mediation by spinal adrenergic and serotonergic receptors. Exp Neurol 2005, 195(2):430-436.
19. Kim W, Kim SK, Min BI: Mechanisms of electroacupuncture-induced analgesia on neuropathic pain in animal model. Evidence-based Complement Alternative Med 2013, 2013:436913.

20. Zimmermann M: Ethical guidelines for investigations of experimental pain in conscious animals. Pain 1983, 16(2):109-110

21. Ling B, Coudore-Civiale MA, Balayssac D, Eschalier A, Coudore F, Authier N: Behavioral and immunohistological assessment of painful neuropathy induced by a single oxaliplatin injection in the rat. Toxicology 2007, 234(3): 176-184.

22. Ling B, Coudore F, Decalonne L, Eschalier A, Authier N: Comparative antiallodynic activity of morphine, pregabalin and lidocaine in a rat model of neuropathic pain produced by one oxaliplatin injection. Neuropharmacology 2008, 55(5):724-728.

23. Kim YI, Na HS, Yoon YW, Han HC, Ko KH, Hong SK: NMDA receptors are important for both mechanical and thermal allodynia from peripheral nerve injury in rats. Neuroreport 1997, 8(9-10):2149-2153.

24. Na HS, Han JS, Ko KH, Hong SK: A behavioral model for peripheral neuropathy produced in rat's tail by inferior caudal trunk injury. Neurosci Lett 1994, 177(1-2):50-52.

25. Yin CS, Jeong HS, Park HJ, Baik Y, Yoon MH, Choi CB, Koh HG: A proposed transpositional acupoint system in a mouse and rat model. Res Vet $\mathrm{SCi}$ 2008, 84(2):159-165.

26. Zhu JX, Zhu XY, Owyang C, Li Y: Intestinal serotonin acts as a paracrine substance to mediate vagal signal transmission evoked by luminal factors in the rat. J Physiol 2001, 530(Pt 3):431-442.

27. Maleki N, Nayebi AM, Garjani A: Effects of central and peripheral depletion of serotonergic system on carrageenan-induced paw oedema. Int Immunopharmacol 2005, 5(12):1723-1730.

28. De la Calle $\mathrm{J}$, , Paino $\mathrm{CL}$ : A procedure for direct lumbar puncture in rats. Brain Res Bull 2002, 59(3):245-250

29. Solomon RE, Brody MJ, Gebhart GF: Pharmacological characterization of alpha adrenoceptors involved in the antinociceptive and cardiovascular effects of intrathecally administered clonidine. J Pharmacol Exp Ther 1989, 251(1):27-38.

30. Mjellem N, Lund A, Hole K: Different functions of spinal 5-HT1A and 5-HT2 receptor subtypes in modulating behaviour induced by excitatory amino acid receptor agonists in mice. Brain Res 1993, 626(1-2):78-82.

31. Sasaki M, Ishizaki K, Obata H, Goto F: Effects of 5-HT2 and 5-HT3 receptors on the modulation of nociceptive transmission in rat spinal cord according to the formalin test. Eur J Pharmacol 2001, 424(1):45-52.

32. Radhakrishnan R, King EW, Dickman JK, Herold CA, Johnston NF, Spurgin ML, Sluka KA: Spinal 5-HT(2) and 5-HT(3) receptors mediate low, but not high, frequency TENS-induced antihyperalgesia in rats. Pain 2003, 105(1-2):205-213.

33. Glowinski J, Iversen LL: Regional studies of catecholamines in the rat brain. I. The disposition of [3H]norepinephrine, $[3 \mathrm{H}]$ dopamine and $[3 \mathrm{H}]$ dopa in various regions of the brain. J Neurochem 1966, 13(8):655-669.

34. Kang SY, Kim CY, Roh DH, Yoon SY, Park JH, Lee HJ, Beitz AJ, Lee JH: Chemical stimulation of the ST36 acupoint reduces both formalin-induced nociceptive behaviors and spinal astrocyte activation via spinal alpha-2 adrenoceptors. Brain Res Bull 2011, 86(5-6):412-421.

35. Kang SY, Roh DH, Yoon SY, Moon JY, Kim HW, Lee HJ, Beitz AJ, Lee JH: Repetitive treatment with diluted bee venom reduces neuropathic pain via potentiation of locus coeruleus noradrenergic neuronal activity and modulation of spinal NR1 phosphorylation in rats. J Pain 2012, 13(2):155-166

36. Bardin L, Bardin M, Lavarenne J, Eschalier A: Effect of intrathecal serotonin on nociception in rats: influence of the pain test used. Exp Brain Res 1997, 113(1):81-87.

37. Xie DJ, Uta D, Feng PY, Wakita M, Shin MC, Furue $H$, Yoshimura $M$ Identification of 5-HT receptor subtypes enhancing inhibitory transmission in the rat spinal dorsal horn in vitro. Mol Pain 2012, 8:58.

38. Schmauss C, Hammond DL, Ochi JW, Yaksh TL: Pharmacological antagonism of the antinociceptive effects of serotonin in the rat spinal cord. Eur $J$ Pharmacol 1983, 90(4):349-357.

39. Aimone LD, Jones SL, Gebhart GF: Stimulation-produced descending inhibition from the periaqueductal gray and nucleus raphe magnus in the rat: mediation by spinal monoamines but not opioids. Pain 1987, 31(1):123-136.

40. Hammond DL, Yaksh TL: Antagonism of stimulation-produced antinociception by intrathecal administration of methysergide or phentolamine. Brain Res 1984, 298(2):329-337. 
41. Jeong HJ, Mitchell VA, Vaughan CW: Role of 5-HT(1) receptor subtypes in the modulation of pain and synaptic transmission in rat spinal superficial dorsal horn. Br J Pharmacol 2012, 165(6):1956-1965.

42. Bardin L: The complex role of serotonin and $5-H T$ receptors in chronic pain. Behav Pharmacol 2011, 22(5-6):390-404.

43. Giordano J, Schultea T: Serotonin 5-HT(3) receptor mediation of pain and anti-nociception: implications for clinical therapeutics. Pain Physician 2004, 7(1):141-147.

44. Bilge SS, Bozkurt A, Ilkaya F, Ciftcioglu E, Kesim Y, Uzbay TI: The antinociceptive effects of intravenous tianeptine in colorectal distension-induced visceral pain in rats: the role of 5-HT(3) receptors. Eur J Pharmacol 2012, 681(1-3):44-49.

45. Paul D, Yao D, Zhu P, Minor LD, Garcia MM: 5-hydroxytryptamine3 (5-HT3) receptors mediate spinal 5-HT antinociception: an antisense approach. J Pharmacol Exp Ther 2001, 298(2):674-678.

doi:10.1186/1472-6882-14-471

Cite this article as: Lee et al:: Serotonergic mechanism of the relieving effect of bee venom acupuncture on oxaliplatin-induced neuropathic cold allodynia in rats. BMC Complementary and Alternative Medicine 2014 14:471.

\section{Submit your next manuscript to BioMed Central and take full advantage of:}

- Convenient online submission

- Thorough peer review

- No space constraints or color figure charges

- Immediate publication on acceptance

- Inclusion in PubMed, CAS, Scopus and Google Scholar

- Research which is freely available for redistribution 